\title{
Long-term noninvasive single photon emission computed tomography monitoring of perfusional changes after EC-IC bypass surgery
}

\author{
V DI PIERO, G L LENZI, M COLLICE, † F TRIULZI,* P GERUNDINI,* \\ D PERANI,* A R SAVI,* C FIESCHI, F FAZIO*
}

From III Neurological Clinic, Department of Neurological Sciences, University of Rome, Department of Biomedical Technology, S. Raffaele Institute, University of Milan, ${ }^{*}$ and Department of Neurosurgery, Niguarda Hospital, $\uparrow$ Milan, Italy

SUMMARY The rCBF was evaluated using I-123 HIPDM and single photon emission computed tomography (SPECT) on 14 patients undergoing extracranial-intracranial (EC-IC) bypass surgery because of internal carotid artery (ICA) occlusion. Before surgery, all patients showed cortical areas of hypoperfusion over the affected cerebral hemisphere. Shortly after EC-IC bypass a rCBF increase was observed in six patients. However, at the 6 and 12 month follow-ups, with angiographic control of bypass patency, rCBF studies did not show any significant rCBF change. Long-term noninvasive tomographic monitoring of perfusion changes occurring after EC-IC bypass surger failed to show a long-lasting improvement in perfusion.

The prevention of new ischaemic episodes has been the main goal of extracranial-intracranial (EC-IC) bypass surgery. However, the results of the International EC-IC Bypass Study Group ${ }^{1}$ indicate the failure of EC-IC bypass to reduce the recurrence of ischaemic stroke in comparison with conventional medical treatment. Nevertheless, the lack of data in this clinical study regarding physiological parameters, such as metabolism and perfusion, does not exclude the possibility, among the population examined, of the presence of subgroups of patients responsive to this revascularisation surgery. ${ }^{2}$

Previous studies have been devoted to the evaluation of the haemodynamic or metabolic effects of revascularisation within a short time after surgery. Results seemed to indicate short-term benefits from the procedure, with eventual neurological and psychological improvements ${ }^{3-9}$ parallelling the increase of perfusional and metabolic measurements. On the other hand, few reports have dealt with the evaluation of the long-term haemodynamic effects of EC-IC bypass surgery and data in the literature are highly debatable.

Therefore, we have evaluated both the short and

Address for reprint requests: V Di Piero MD, Department of Neurological Sciences, V. le dell'Universita' N. 30, 00183 Roma, Italy.

Received 12 August 1986. Accepted 23 September 1986. long term haemodynamic effects of EC-IC bypas\& surgery by means of single photon emission comp puted tomography (SPECT) and I-123 HIPDM, 迎 perfusion imaging agent developed by Kung et al $\stackrel{10}{\overrightarrow{0}} \cdot \overrightarrow{\overrightarrow{0}}$ and utilised both in experimental and in clinical studies. ${ }^{1112}$

\section{Patients and methods}

We studied 14 patients ( 13 males and one female) ranging from 42 to 73 years of age (mean age 56.8 \pm 8.9). All patients had had one or more episodes of cerebral ischaemia with occlusion of the internal carotid artery (ICA) on the same side of the symptomatic cerebral hemisphere.

We excluded all patients with: (a) cerebral ischaemic episodes affecting more than one vascular territory, $(b)$ severe neurological deficits, $(c)$ large or multiple areas of hypodensity at CT scan, (d) time interval from the last neurological episode of less than 2 months.

The study's protocol included: a full neurological evaluation, complete four-vessel cerebral angiography, cerebral $\mathrm{CT}$ scan and a regional cerebral blood flow (rCBF) study, all to be performed before $(10 \pm 14$ days) and after $(10 \pm 12$ days) EC-IC bypass surgery. Only one patient (case No 10) had angiographic evidence of severe multiple lesions of the cerebral vessels.

Further follow-up studies were obtained on 11 patients at 6 months (189 \pm 20 days) and on 10 at 12 months (498 $\pm 77 \mathrm{~N}$ days) after surgery. At each study, neurological examination, cerebral CT scan and $\mathrm{rCBF}$ evaluation were re- 
Table 1 Clinical presentation

\begin{tabular}{|c|c|c|c|c|c|c|c|c|}
\hline \multirow[b]{2}{*}{ Patient } & \multirow{2}{*}{$\begin{array}{l}\text { Age/sex } \\
(y r)\end{array}$} & \multirow{2}{*}{ Diagnosis } & \multirow{2}{*}{$\begin{array}{l}\text { Days since } \\
\text { last } \\
\text { ischaemic } \\
\text { episode }\end{array}$} & \multirow[b]{2}{*}{ Motor deficit } & \multicolumn{2}{|l|}{ CT scan hypodensity } & \multirow{2}{*}{$\begin{array}{l}\text { Pre-operative } \\
\text { angiography }\end{array}$} & \multirow{2}{*}{$\begin{array}{l}\text { Last } \\
\text { bypass } \\
\text { patency } \\
\text { control }\end{array}$} \\
\hline & & & & & Location & Size & & \\
\hline 1 & $45 / M$ & Stroke & 144 & Mild $\mathbf{R}$ hemiparesis & $\begin{array}{l}\text { Watershed territory of } \\
\text { L ACA/MCA }\end{array}$ & $\mathbf{S}$ & L ICA occlusion & DVA \\
\hline 2 & $\begin{array}{l}62 / M \\
42 / M\end{array}$ & $\begin{array}{l}\text { RIA } \\
\text { Stroke }\end{array}$ & $\begin{array}{r}65 \\
120\end{array}$ & $\begin{array}{l}\text { Absent } \\
\text { Mild L hemiparesis }\end{array}$ & $\begin{array}{l}\text { Absent } \\
\text { Deep territory of } \\
\text { R MCA }\end{array}$ & $\bar{s}$ & $\begin{array}{l}\text { L ICA occlusion } \\
\text { R ICA occlusion }\end{array}$ & $\begin{array}{l}\text { DVA } \\
\text { DVA }\end{array}$ \\
\hline 4 & 47/M & Stroke & 66 & $\begin{array}{l}\text { Very mild } \mathbf{R} \\
\text { hemiparesis }\end{array}$ & $\begin{array}{l}\text { Cortical posterior half } \\
\text { L MCA }\end{array}$ & $\mathbf{M}$ & L ICA occlusion & DAA \\
\hline $\begin{array}{l}5 \\
6\end{array}$ & $\begin{array}{l}60 / \mathrm{M} \\
67 / \mathrm{F}\end{array}$ & $\begin{array}{l}\text { RIA } \\
\text { Stroke }\end{array}$ & $\begin{array}{r}350 \\
60\end{array}$ & $\begin{array}{l}\text { Absent } \\
\text { Mild L hemiparesis }\end{array}$ & $\begin{array}{l}\text { Absent } \\
\text { Watershed territory of } \\
\text { R ACA/MCA }\end{array}$ & $\bar{s}$ & $\begin{array}{l}\text { R ICA occlusion } \\
R \text { ICA occlusion }\end{array}$ & $\begin{array}{l}\text { DAA } \\
\text { DVA }\end{array}$ \\
\hline $\begin{array}{r}7 \\
8 \\
9 \\
10\end{array}$ & $\begin{array}{l}52 / \mathrm{M} \\
64 / \mathrm{M} \\
58 / \mathrm{M} \\
55 / \mathrm{M}\end{array}$ & $\begin{array}{l}\text { Stroke } \\
\text { Stroke } \\
\text { RIA } \\
\text { RIA }\end{array}$ & $\begin{array}{r}65 \\
80 \\
177 \\
312\end{array}$ & $\begin{array}{l}\text { Mild L hemiparesis } \\
\text { Mild L hemiparesis } \\
\text { Absent } \\
\text { Absent }\end{array}$ & $\begin{array}{l}\text { Posterior half of R MCA } \\
\text { Deep territory of R MCA } \\
\text { Absent } \\
\text { Deep territory of R MCA }\end{array}$ & $\frac{M}{S}$ & $\begin{array}{l}\text { R ICA occlusion } \\
\text { L ICA occlusion } \\
\text { L ICA occlusion } \\
\text { R ICA occlusion } \\
\text { L ICA and } \\
\text { vertebral artery } \\
\text { stenosis }\end{array}$ & $\begin{array}{l}\text { DAA } \\
\text { DAA } \\
\text { DVA } \\
\text { DVA }\end{array}$ \\
\hline 11 & 49/M & Stroke & 70 & $\begin{array}{l}\text { Very mild } \mathrm{L} \\
\text { hemiparesis }\end{array}$ & Deep R MCA & $\mathbf{S}$ & R ICA occlusion & - \\
\hline $\begin{array}{l}12 \\
13 \\
14\end{array}$ & $\begin{array}{l}\text { 61/M } \\
54 / M \\
62 / M\end{array}$ & $\begin{array}{l}\text { Stroke } \\
\text { RIA } \\
\text { Stroke }\end{array}$ & $\begin{array}{r}60 \\
90 \\
240\end{array}$ & $\begin{array}{l}\text { Mild } \mathbf{R} \text { hemiparesis } \\
\text { Absent } \\
\text { Mild } R \text { hemiparesis }\end{array}$ & $\begin{array}{l}\text { Posterior half of L MCA } \\
\text { Absent } \\
\text { Posterior half of L MCA }\end{array}$ & $\frac{\mathbf{M}}{\mathbf{M}}$ & $\begin{array}{l}\text { L ICA occlusion } \\
\text { R ICA occlusion } \\
\text { L ICA occlusion }\end{array}$ & $\begin{array}{l}\text { DVA } \\
\text { DVA } \\
\text { DVA }\end{array}$ \\
\hline
\end{tabular}

Abbreviations: R, right; L, left; ACA, anterior cerebral artery; MCA, middle cerebral artery; ICA, internal carotid artery; S, small hypodense lesion, maximum diameter $<2 \mathrm{~cm}, \mathrm{M}$, medium hypodense lesion, maximum diameter $<4 \mathrm{~cm}$; DVA, digital venous angiography; DAA, digital arterious angiography.

peated. Further, all patients studied at 12 months after surgery were submitted to digital venous angiography (DVA) to evaluate the patency of EC-IC bypass.

We considered the EC-IC bypass successful when the middle cerebral artery (MCA) appeared refilled from the anastomosis before the contrast reached its lower tract. $\mathrm{Pa}$ tients, with no clear evidence of bypass patency at DVA examination, were submitted to intra-arterial digital angiography (DAA).

Clinical presentations were: five patients with reversible cerebral ischaemic attacks (RIAs) and nine patients with unreversible cerebral ischaemia (stroke) and mild neurological deficits, with or without additional RIAs. In three RIAs and in four strokes, the right ICA was affected and in two RIAs and in five strokes the left (table 1).

Cerebral CT scan was performed with a Toshiba $80 \mathrm{~A}$ (rotate-rotate) scanner, by positioning the patient's head with the orbito-meatal line perpendicular to the horizontal plane.

According to the cerebral CT scan findings, we divided patients into three subgroups: $(a)$ with negative CT scan $(n=4),(b)$ with hypodense area of small size (maximum diameter $<2 \mathrm{~cm}(\mathrm{n}=6)$, and $(c)$ with hypodense area of moderate size (maximum diameter $<4 \mathrm{~cm}(\mathrm{n}=4)$.

EC-IC bypass surgery was performed by the same neurosurgeon $(\mathrm{CM})$ at a mean time interval of from $135 \pm 98$ days after the last neurological episode. There were no clinical or neurological complications after surgery.

Neurological examinations, performed soon after surgery and at follow-up, did not show any evidence of substantial change compared with the pre-operative status.

CBF assessment with SPECT

The following protocol was used to assess $\mathrm{rCBF}$ with SPECT: all the patients were premedicated with potassium iodine solution (Lugol's solution) 15 drops/day, for two days prior to the study. They were given an intravenous injection of 7 (range 5-10) mCi of I-123 HIPDM, while lying supine with eyes closed on a couch, in a room near the gamma-camera. Fifteen minutes after the injection they were transferred to the gamma-camera room and the SPECT study was performed. A commercial rotating gammacamera (GE $400 \mathrm{~T}$, Milwaukee, WI) was used, equipped with a low energy high resolution general purpose parallel hole collimator and dedicated computer. Patients were supine with eyes closed. The head was positioned in a head holder that kept the orbito-meatal (OM) line perpendicular to the floor. The SPECT study was performed by rotating the gamma-camera around the patient and recording 64 angular views on the computer, using a $64 \times 64$ matrix view. For each study 3 to 5 million total counts were recorded for a $360^{\circ}$ rotation around the head lasting 20 to 50 minutes.

All SPECT data were subsequently reconstructed and attenuation corrected using a procedure previously implemented in a clinical setting. ${ }^{13} \mathrm{~A}$ complete set of tomographic slices was thus obtained. Slice thickness was measured to be $2.3 \mathrm{~cm}$ full width at half maximum (FWHM) for one slice. As expected, using planes made by summing two adjacent pixels, slice thickness does not increase proportionally, being $2.5 \mathrm{~cm}$ FWHM. To reduce noise on the reconstruction data, a raised cosine transition low pass filter was used, with a cutoff frequency of $0.4 \mathrm{~cm}^{-1}$. Transaxial average resolution with this filter was $2 \cdot 3 \mathrm{~cm}$ FWHM.

All transaxial reconstructions shown in this paper were obtained by summing the contents of the two adjacent pixels. However, to optimise information available, contiguous 2 -pixel slices were overlapped by 1 pixel. Thus, slice 1 resulted from the sum of rows 1 and 2; slice 2 resulted from the sum of rows 2 and 3, etc. The centre-to-centre distance in $\mathrm{cm}$ $(1$ pixel $=0.64 \mathrm{~cm})$ of each slice from a reference plane was 

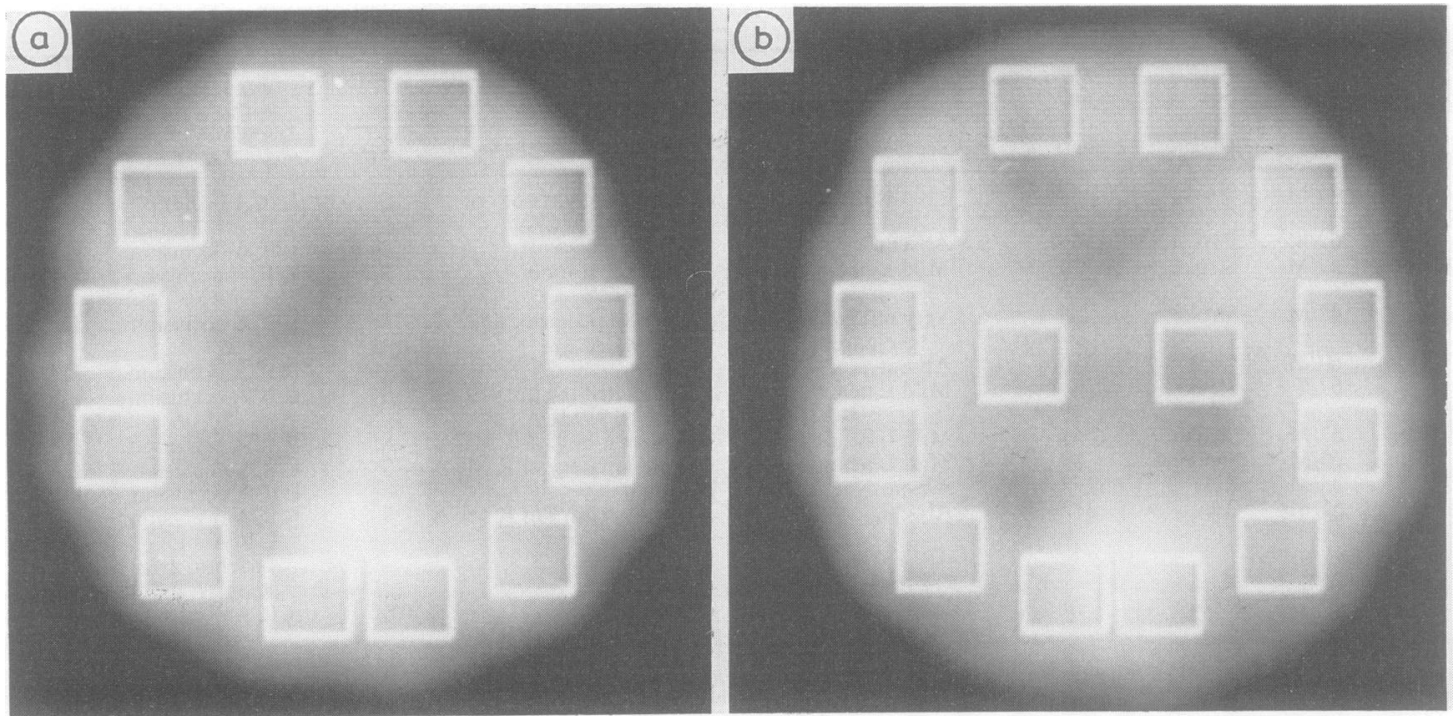

Fig 1 Normal subject. Transaxial I-123 HIPDM tomograms at (a) $6 \mathrm{~cm}$ and (b) $4 \mathrm{~cm}$ above the orbito-meatal line, showing the regions of interest analysed.

then calculated for transaxial slices. The reference horizontal plane was the orbito-meatal (OM) line. Markers (point sources) were used to identify these anatomical locations, by an acquisition made on the lateral view (markers on glabella orbit, auditory meatus) at the end of the study.

\section{CBF data analysis}

Out of the complete tomographic set obtained for each of the patients studied, we considered for each patient two slices at orbito-meatal level plus $4 \mathrm{~cm}(\mathrm{OM}+4)$ and orbitomeatal level plus $6 \mathrm{~cm}(\mathrm{OM}+6)$.

Regions of interest (ROIs) of $4 \times 4$ pixels were chosen on the unaffected cerebral hemisphere and then symmetrically transferred to the contralateral one. Twelve ROIs for $\mathrm{OM}+6$ and 14 ROIs for OM + 4 (fig 1) were considered. For each tomogram, mean hemispheric values were obtained by averaging values of all the ROIs on each side.

Regional and hemispheric ratios were calculated by dividing single ROIs and mean hemispheric values of all the ROIs over the affected side, by those of the contralateral one (affected vs unaffected (A/UA)). The cerebral tomogram with the most evident asymmetry at the pre-operative study was chosen for each patient to be compared with any postoperative changes.

With the evaluation of changes after EC-IC bypass surgery as our goal, we have preferred to estimate the ratio between the cerebral hemispheres which showed very little variations in serial studies, less than $6 \%$ in PET studies on normal subjects, ${ }^{14}$ as opposed to analysing variations among small ROIs. In this regard, Frackowiak et al ${ }^{15}$ observed a variability of more than $60 \%$, in normal subjects, for data analysis on single ROIs.

The choice of ROIs could represent another source of error because of the statistical problems connected with their size and the difficulties involved in delineating, in repeated studies, the same regions in the same subject, for the small differences in head positioning and the lack of internal reference points. Furthermore, it was observed that after surger 6 even if mean hemispheric ratios seemed to show a lesser de्ठ $\infty$ gree of variability than singular ROIs ratios changes, the 0 perfusional effects of the surgical procedure were mainly the same whether considering mean cerebral hemispheric क्ष single ROIs ratios. Thus, we can assume that single ROf variations were well represented by the mean cerebrg hemispheric ratio.

\section{CBF normal values}

Regional and mean hemispheric $\mathrm{CBF}$ ratios were calculated in seven normal subjects (mean age 28 years (range 19-41 years)). Mean left/right hemispheric ratios were the following: for $O M+6$ tomogram: $L / R: 1 \cdot 01 \pm 0 \cdot 048$; for $O M+4$ tomogram: $L / R: 1.02 \pm 0.046$.

A variation of the hemispheric ratio of more than 2 SD $\stackrel{\varnothing}{\varnothing}$ from the mean normal value was considered statistically $\overrightarrow{\vec{B}}$ significant. Expressing the mean normal ratio as 100 , the $\frac{0}{3}$ normal range for OM + 6 tomogram was $90 \cdot 5-109 \cdot 5$, and for $\mathrm{OM}+4$ tomogram 91-109.

In addition the variability with time of the mean hemispheric ratios in five patients with established cerebral infarct, studied twice at 6 month intervals between the two studies, was also considered. In this study (Lenzi et al, in preparation) the average of the mean hemispheric (A/UA) 3 . ratios had changed from 92.03 to 91.94 , with variations $\delta$ ranging from $-8 \%$ to $+5 \%(\mathrm{mv} 4 \cdot 2 \% \pm 2 \cdot 77)$.

\section{Statistical analysis}

Statistical evaluation of the results was done using Student's $t$ test for paired observations, for results obtained within the same group of patients, and unpaired Student's $t$ test and $N$ Dunnett's test for comparison of results taken from different groups. 
Table 2 I-123 HIPDM SPECT study: percent variations of the cerebral hemispheric ratio $(A / U A)$ in respect to normal values before and after EC-IC bypass surgery

\begin{tabular}{|c|c|c|c|c|}
\hline Patient & Pre-op & Post-op & $\begin{array}{l}\text { follow-up } \\
\text { foll }\end{array}$ & $\begin{array}{l}\text { II } \\
\text { follow-up }\end{array}$ \\
\hline $\begin{array}{l}1 \\
2 \\
3 \\
4 \\
5 \\
6 \\
7 \\
8 \\
9 \\
10 \\
11 \\
12 \\
13 \\
14 \\
\text { Mean } \\
\text { SD }\end{array}$ & $\begin{array}{r}78 \cdot 2 \\
70 \cdot 6 \\
85 \cdot 4 \\
71 \cdot 6 \\
89 \cdot 8 \\
88 \cdot 8 \\
64 \cdot 3 \\
83 \cdot 3 \\
91 \cdot 2 \\
91 \cdot 8 \\
98 \cdot 0 \\
74 \cdot 5 \\
100 \cdot 0 \\
54 \cdot 5 \\
81 \cdot 57 \\
\pm 13 \cdot 18\end{array}$ & $\begin{array}{c}89 \cdot 1 \\
88 \cdot 2 \\
91 \cdot 7 \\
88 \cdot 8 \\
93 \cdot 1 \\
88 \cdot 8 \\
85 \cdot 7 \\
97 \cdot 1 \\
96 \cdot 1 \\
113 \cdot 3 \\
111 \cdot 2 \\
93 \cdot 1 \\
104 \cdot 1 \\
67 \cdot 3 \\
93 \cdot 40 \\
\pm 11 \cdot 37\end{array}$ & $\begin{array}{r}89.1 \\
88.2 \\
94.8 \\
76.5 \\
99.0 \\
93.9 \\
60.2 \\
83.3 \\
88.2 \\
87.8 \\
115.3\end{array}$ & $\begin{array}{l}90.1 \\
83.3 \\
94.8 \\
75.5 \\
93.6 \\
93.9 \\
65.3 \\
84.3 \\
96.5 \\
88.8\end{array}$ \\
\hline
\end{tabular}

\section{Results}

\section{GLOBAL ANALYSIS}

Pre-operative SPECT The pre-operative rCBF studies in nine patients (eight strokes and one RIA) showed a significant decrease of perfusion over all the affected cerebral hemisphere. In the other five patients (one stroke and four RIAs) a mean cerebral hemispheric ratio within normal range was observed. However, considering single ROI ratios, a focal decrease of I-123 HIPDM uptake out of the normal range was present, confined to one or more welldefined cerebral regions, corresponding to the neurological symptoms experienced.

Mean hemispheric ratio (A/UA) in the preoperative study was $81.57 \pm 13.18$ which is significantly reduced compared with normal values (table 2).

Cerebral perfusion was obviously more markedly reduced in stroke patients ( $\mathrm{mv} 77.62 \pm 13 \cdot 19)$ than in RIA ones (mv 88.68 \pm 10.87 ) but there were no statistically significant differences between the two groups (table 3).

Patients with hypodense areas of moderate size showed a greater decrease of rCBF than patients with small sized areas or with normal cerebral CT scan, even if there was no statistical difference among these groups. No statistical difference was observed according to age or to the time interval elapsed from the last neurological episode.

We decided to label as "high perfusion deficit" (HPD) the asymmetries exceeding 4 SD from the normal mean hemispheric ratio (lower than 81). This HPD group included one RIA and four strokes. The remaining patients ("low perfusion deficit" (LPD)) were presenting with four RIAs and five strokes.

Early post-operative SPECT In respect to the preoperative studies there was a significant global increase of $\mathrm{rCBF}(+12.66 \%$; $\mathrm{p}<0.05)$. It was more pronounced in patients with stroke than in patients with RIA. Considering the size of hypodense CT scan cerebral lesions, it was more pronounced when the lesion was of moderate size. Nevertheless, no statistically significant variations compared with the preoperative perfusional state were observed among either of these subgroups.

A more marked statistically significant increase was observed in the HPD group $(+24.96 \% ; p<0.05)$ than in the LPD group $(+8.62 \%$; not significant (NS)).

Six month follow-up SPECT A six month follow-up study was performed in 11 patients, four RIAs and seven strokes. Two more patients, one RIA and one stroke, refused further studies and one patient died of gastrointestinal cancer.

The total mean hemispheric $\mathrm{rCBF}$ ratio (A/UA) presented a relative increase of $+8.09 \%$ (NS) com-

Table 3 I-123 HIPDM SPECT study: mean percent variations of the hemispheric ratio $(A / \mu A)$ in respect to normal values before and after EC-IC bypass surgery according to clinical diagnosis, cerebral CT scan findings and the degree of the pre-operative perfusion deficit

\begin{tabular}{|c|c|c|c|c|}
\hline & Pre-op & Post-op & I follow-up & II follow-up \\
\hline $\begin{array}{l}\text { Clinical diagnosis } \\
\text { RIA } \\
\text { Stroke } \\
\text { Total }\end{array}$ & $\begin{array}{l}88.68 \pm 10.87(n=5) \\
77.62 \pm 13.19(n=9) \\
81.57 \pm 13.18(n=14)\end{array}$ & $\begin{array}{l}98 \cdot 10 \pm 10.67 \quad(n=5) \\
90.79 \pm 11.47 \quad(n=9) \\
93.40 \pm 11.37^{*}(n=14)\end{array}$ & $\begin{array}{l}90.80 \pm 4.74(\mathrm{n}=4) \\
87.59 \pm 17 \cdot 10(\mathrm{n}=7) \\
88.75 \pm 13.67(\mathrm{n}=11)\end{array}$ & $\begin{array}{l}90.55 \pm 5.78(n=4) \\
83.98 \pm 11.6(n=6) \\
86.61 \pm 9.87(n=10)\end{array}$ \\
\hline $\begin{array}{l}\text { Cerebral CT scan } \\
\text { Negative } \\
\text { Small } \\
\text { Moderate }\end{array}$ & $\begin{array}{l}\text { indings } \\
87.90 \pm 12 \cdot 39(n=4) \\
87.34 \pm 7.70(n=5) \\
70.74 \pm 11 \cdot 37(n=5)\end{array}$ & $\begin{array}{r}94.30 \pm 6.46 \quad(n=4) \\
100.48 \pm 11.15 \quad(n=5) \\
85.60 \pm 9.57 \quad(n=5)\end{array}$ & $\begin{array}{l}91.80 \pm 5.09(n=3) \\
94.06 \pm 11.2(n=5) \\
76.87 \pm 11.85(n=3)\end{array}$ & $\begin{array}{l}91 \cdot 13 \pm 6.93(n=3) \\
89.50 \pm 4.31(n=4) \\
78.23 \pm 14.49(n=3)\end{array}$ \\
\hline $\begin{array}{l}\text { Degree of pre-oper } \\
\text { Low PD } \\
\text { High PD }\end{array}$ & $\begin{array}{l}\text { ative perfusion deficit (PD) } \\
91.03 \pm 5.70(\mathrm{n}=9) \\
68.95 \pm 8.44(\mathrm{n}=5)\end{array}$ & $\begin{array}{l}98.88 \pm 9.03(n=9) \\
86.16 \pm 9.64^{*}(n=5)\end{array}$ & $\begin{array}{l}94.61 \pm 9.73(n=7) \\
78.50 \pm 11.67(n=4)\end{array}$ & $\begin{array}{r}91.98 \pm 4.56(n=6) \\
78.55 \pm 10.65(n=4)\end{array}$ \\
\hline
\end{tabular}

${ }^{*} \mathrm{p}<0.05$ (Dunnett's test). 
pared with the pre-operative study.

No statistically significant changes were observed in clinical diagnosis, cerebral CT scan findings and degree of pre-operative perfusion deficit (HPD = one RIA and three strokes; LPD = three RIAs and four strokes).

One year follow-up SPECT The second follow-up study was performed in 10 of the previous patients (four RIAs and six strokes); one patient died of a cause unrelated to the present study.

Mean hemispheric rCBF ratio did not change significantly from the previous follow-up, showing a slight increase of +5.81 (NS) in respect to the preoperative study.

This last follow-up did not show any significant differences from the previous perfusion evaluations, even when considering the three subgroups of patients according to clinical diagnosis, cerebral CT scan findings and degree of the pre-operative perfusion deficit (HPD = one RIA and three strokes; LPD $=$ three RIAs and three strokes).

INDIVIDUAL ANALYSIS

Statistical analysis of small populations is very controversial and the results must be taken with extreme caution. Bearing this in mind, on the basis of the statistical analysis of changes in side-to-side ratios in normal patients and on their variations observed in the study of reproducibility in patients with stable ischaemic lesions, a variation in asymmetry larger than $20 \%$ was considered to be significant.

After surgery, out of 14 patients only six showed a significant reduction of the pre-existing asymmetry at the early post-operative follow-up (table 4). Two had RIAs and four were strokes. A patient with RIA had a negative cerebral CT scan while the other presented a small hypodense lesion in the right internal capsule.

Table 4 I-123 HIPDM SPECT study: percentage change of cerebral hemispheric ratio $(A / U A)$ after $E C-I C$ bypass surgery

\begin{tabular}{|c|c|c|c|}
\hline Patient & Post-op & $\begin{array}{l}\text { follow-up } \\
\text { fow }\end{array}$ & $\begin{array}{l}\text { II } \\
\text { follow-up }\end{array}$ \\
\hline $\begin{array}{l}1 \\
2 \\
3 \\
4 \\
5 \\
6 \\
7 \\
8 \\
9 \\
10 \\
11 \\
12 \\
13 \\
14 \\
\text { Mean } \\
\text { SD }\end{array}$ & $\begin{array}{l}+13.9 \\
+24.9^{*} \\
+7.4 \\
+30.0^{*} \\
-1 \cdot 1 \\
0.0 \\
+33 \cdot 3^{*} \\
+16.6 \\
+5 \cdot 4 \\
+23.4^{*} \\
+13.5 \\
+25 \cdot 0^{*} \\
+4 \cdot 1 \\
+23.5^{*} \\
+15.71 \\
\pm 11.28\end{array}$ & $\begin{array}{l}+13.9 \\
+24.9 * \\
+11.0 \\
+6.8 \\
+10.2 \\
+5.7 \\
-6.4 \\
0.0 \\
-3.3 \\
-4.4 \\
+17.7\end{array}$ & $\begin{array}{l}+15.2 \\
+18.0 \\
+11.0 \\
+5.4 \\
+4.0 \\
+5.7 \\
+3.3 \\
+1.2 \\
+5.8 \\
-3.3\end{array}$ \\
\hline
\end{tabular}

*Significant variation (see text).
Patients with strokes all had a cortical hypodense lesion of moderate size.

At the 6 month follow-up, only one patient (case No 2) still showed a clear improvement of the pre-operative perfusion asymmetry. The other five showed no significant changes compared with the preoperative $\mathrm{rCBF}$ ratios.

At the one year follow-up, none of the patients differed significantly from the pre-operative perfusional state.

\section{Discussion}

The haemodynamic balance in patients with occlusive disease of the neck and/or the intracranial circulation has been widely studied, in particular with PET techniques, which led to the precise identification of the situation called "misery perfusion". ${ }^{16}$ In this situation, the reduction in local CBF is paralleled by an increase of the oxygen extraction ratio (OER) well above normal values; this is a mechanism which allows sufficient oxygen consumption despite reduced blood flow, but which reduces the reserve available for further functional demands. Thus it may lead to the appearance of neurological symptoms if a further haemodynamic alteration occurs, such as a fall ino blood pressure.

Grubb et $a l^{17}$ and Baron et $a l^{18}$ showed a reversa of the misery perfusion state, with a coupled increas of $\mathrm{CBF}$ and of the cerebral oxygen metabolism $\left(\mathrm{CMRO}_{2}\right)$, after EC-IC bypass surgery. However after these first encouraging reports, the descriptions of pathophysiological changes in the cerebral energy balance occurring after the EC-IC bypass surgery have been very controversial.

Powers et al $^{19}$ demonstrated in six out of 17 patients an increase of CBF coupled with a reduction of OER but without any change in $\mathrm{CMRO}_{2}$. This suggested an adequate pre-operative compensation for the lower CBF by an increased OER. On the contrary, Samson et $a^{20}$ showed a parallel increase of $\mathrm{CBF}$ and $\mathrm{CMRO}_{2}$ in both cerebral hemispheres after EC-IC bypass surgery but without any effect on the OER. They did not try to explain the mechanism behind this bilateral metabolic improvement and only suggested a long standing haemodynamic depression of metabolism, still potentially reversible through surgery. In this study, the authors investigated only stroke patients and analysed exclusively the "periinfarct" zone, excluding the areas of hypodensity shown by CT scan. In addition, their data analysis, based on single, small circular ROIs, may have increased the variability of the values.

The assessment of regional cerebral metabolism is in principle the ideal method by which to select patients with ICA occlusion for surgery, depending on the presence or not of a fixed metabolic defect. How- 
ever, less sophisticated investigations, limited to $C B F$ only, have been utilised in evaluating perfusional changes related to revascularisation.

Yamamoto et $\mathrm{al}^{21}$ using positron emission tomography with $\mathrm{Kr}-77$ found a persistent increase of $\mathrm{CBF}$ as a result of EC-IC anastomosis for up to 17 months after surgery. Two-dimensional studies on CBF by using Xe-133 techniques have demonstrated a stable improvement of CBF over the operated cerebral hemisphere whether short-term ${ }^{3422-25}$ or long-term after surgery. ${ }^{26} 27$

In contrast, other authors, ${ }^{28-31}$ using the same techniques, have observed a transient increase early after surgery followed by a progressive return to the pre-operative condition with time, but a threedimensional study with $\mathrm{Xe}-133^{32}$ reported a significant CBF increase soon after EC-IC bypass surgery in only two out of the 22 patients with decreased pre-operative CBF values.

Thus previously published data on CBF have not been unequivocal for the different techniques employed, ${ }^{33}$ or for time interval considered or for clinical selection of patients.

In our study, an asymmetric regional CBF ratio, indicating reduced perfusion over the symptomatic cerebral areas, in comparison with the contralateral side, was observed in all the patients studied. In five of them, the mean hemispheric perfusion asymmetry fell into the normal range but on analysing the ratios among single ROIs it was possible to detect well defined regions of statistically significant decreased perfusion related to the clinical neurological symptomatology experienced.

The perfusion deficit was more pronounced in patients with stroke and the area of hypoperfusion demonstrated by the SPECT study was more extended than the corresponding hypodense area at the cerebral CT scan. Furthermore, a reduced perfusion was also detected in patients with RIAs and normal CT scan.

The detection of regions of cerebral hypoperfusion not corresponding to areas of structural damage at CT scan might be related either to the presence of a reversible haemodynamic condition (such as a misery or critical perfusion syndrome), or to a stabilised incomplete infarction or to disconnection phenomena (diaschisis) with a coupled reduction of $\mathrm{CBF}$ and metabolic demand.

Unfortunately, our lack of metabolic data made it impossible to identify with certainty a condition of critical perfusion. However, PET studies have also frequently failed to show clearly a pattern of decreased CBF, normal $\mathrm{CMRO}_{2}$ and increased OER, in patients with ICA occlusion, underlining the importance of the vasodilatatory response, and therefore of CBV assessment, as the first mechanism of compensation in cerebral ischaemia.
Theoretically, only in a later phase could CBF become inadequate and cause the rise of the OER. With this in mind many authors have pointed out the value of investigating the $\mathrm{CBF} / \mathrm{CBV}$ ratio or $\mathrm{CO}_{2}$ vasoreactivity in order to assess the perfusion reserve and the effects of EC-IC bypass surgery. ${ }^{19242834-38}$ Nevertheless, even data on changes of CBV and vasoreactivity after EC-IC bypass are inconsistent, showing either a reduced $\mathrm{CBV}^{343738}$ and an increased $\mathrm{CO}_{2}$ reactivity ${ }^{24}$ or no variations of these parameters ${ }^{1928}$ after surgery.

In the entire group of our patients soon after EC-IC bypass surgery, an increase of the perfusion over the operated cerebral hemisphere was observed, which was more evident in stroke patients with low pre-operative rCBF values and larger cortical hypodense lesions. At follow-up, an increased perfusion, although not statistically significant was still present in stroke patients. RIA patients did not show any changes either a short or at a long time after surgery. After a transient increase in six out of the 14 patients, at the one year follow-up, there was no longer any change compared with the pre-operative conditions (figs 2,3).

Unlike the patients in previous studies, all ours but one showed no other significant pathological alterations of the neck vessels and of the intracerebral circulation, except for the unilateral ICA occlusion. Furthermore, the present study is the first to have directly checked the EC-IC bypass patency by angiography either shortly or a long time after surgery.

The transient rCBF increase observed might probably be only an epiphenomenon due to increased blood supply to cerebral regions with impaired vasoregulatory mechanisms. (It was evident that cerebral functions were and remained unmodified.) This hypothesis is supported by the findings on cerebral autoregulation in chronic infarcts by Symon et al. ${ }^{39}$ They observed, in baboons, a continuing exhaustion of the autoregulatory capacity and $\mathrm{CO}_{2}$ reactivity, complete in the infarct and progressively less severe in the periinfarct tissue. Consistent with these data, we observed that rCBF improvement occurred preferentially in subjects with extensive cortical infarcts compared with patients with negative or minimal positive cerebral CT scan.

Moreover, the gradual decline with time of the initial increase of perfusion after surgery could indicate that there was no relation between the relatively major blood flow supply achieved and the effective needs of the cerebral tissue involved. Since all of our patients were in a chronic phase, that is more than 2 months after the last neurological episode, it may very likely be that a compensatory mechanism had just taken place, furnishing an adequate (even if at a lower rate) blood flow in relation to the metabolic requirements of the still viable tissue. Furthermore, no im- 

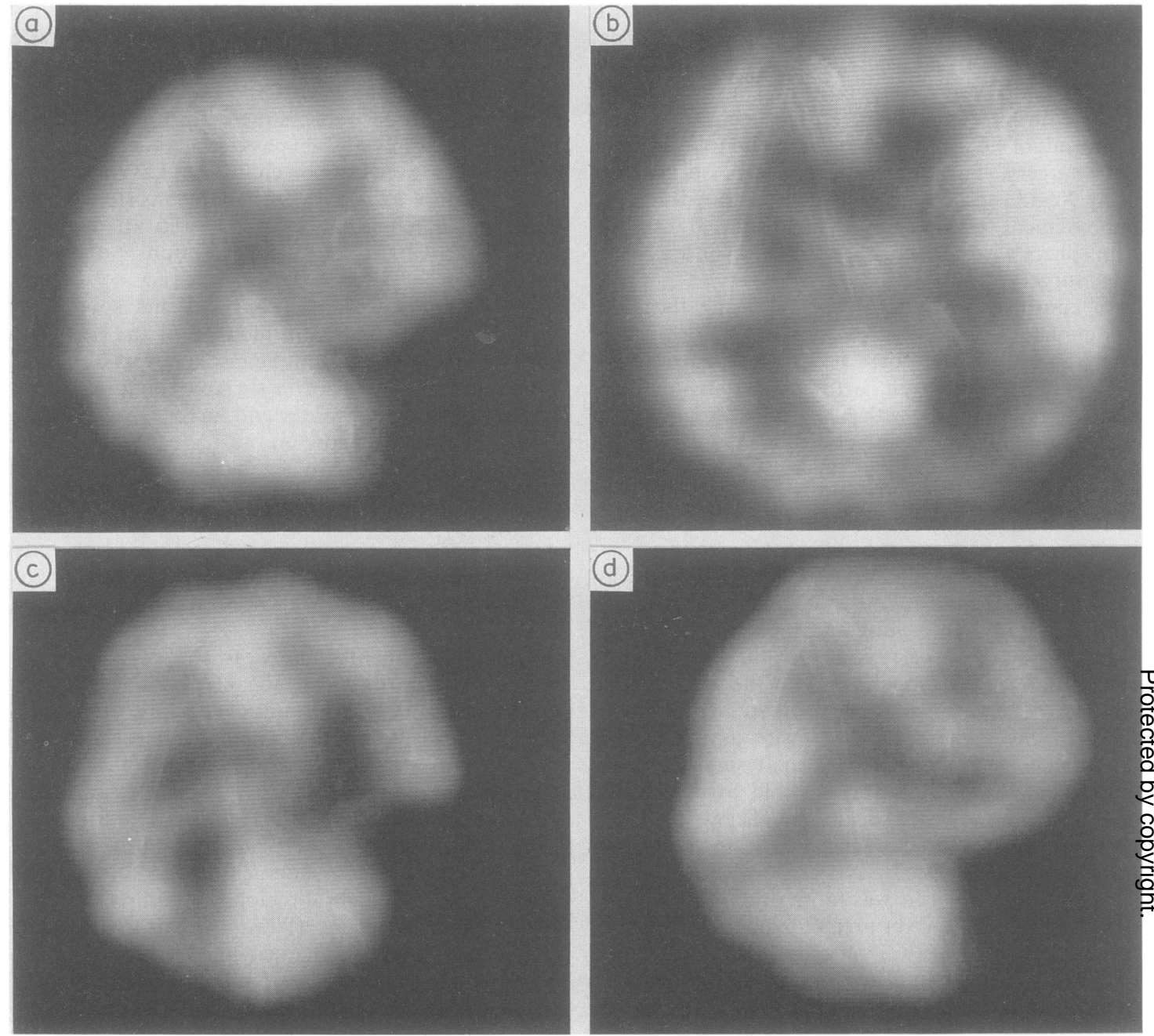

Fig 2 Case No 4. The I-123 HIPDM SPECT studies (tomogram at orbito-meatal line $+4 \mathrm{~cm}$ ) show: (a) a markedly decreased activity over the right cerebral hemisphere pre-operatively; $(b)$ an increase of activity in the previously hypoperfused areas soon after EC-IC bypass surgery; a return to the pre-operative perfusional state at (c) 6 and (d) 12 month follow-up controls.

provement of the clinical conditions was observed after surgery.

In conclusion, long-term assessment of perfusional changes occurring after EC-IC bypass surgery in various subgroups of patients with an ICA occlusion did not provide evidence of any long-lasting perfusional benefit.

As pointed out by Barnett et $a l^{40}$ there are two main end results concerning EC-IC bypass surgery: (a) the functional recovery of the marginal zone of imperfectly functioning yet still viable tissue in the periphery of an infarction, and $(b)$ the reduction of new ischaemic episodes in patients with disease of middle cerebral artery or internal carotid artery not accessible to extracranial artery surgery.

The recent conclusion that the EC-IC bypass procedure does not reduce the risk of ischaemic stroke in comparison with medical therapy ${ }^{1}$ still leaves the first point unresolved.

Our study was aimed at detecting the pathophysiological effects occurring after EC-IC bypass surgery, using a non-invasive, low cost method, potentially available at all nuclear medicine centres. Studies of perfusion with emission tomography are 


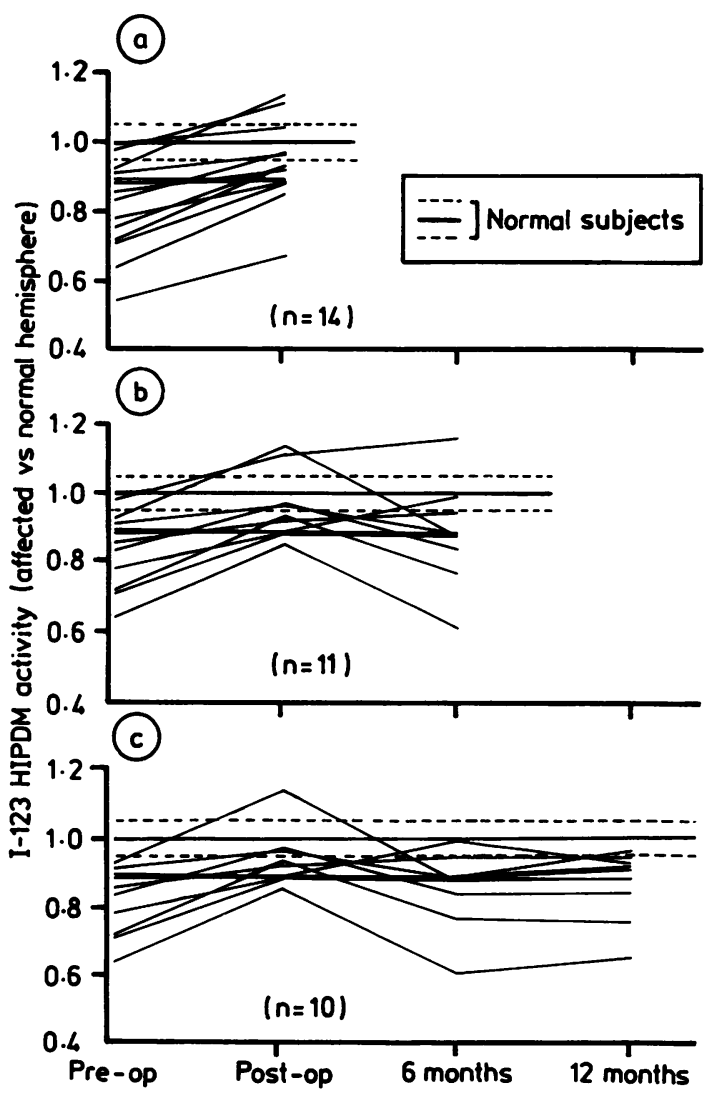

Fig 3 Perfusional effects of EC-IC bypass surgery: (a) early post-operative, (b) 6 and (c) 12 month follow-up studies. (Ordinate: mean cerebral hemispheric I-123 HIPDM activity ratio (A/UA); Abscissa: time; dotted lines show $8 \pm I S D$ of normal subjects.)

limited by the still unresolved problems of SPECT methodology (that is, poor spatial resolution; inaccurate correction for attenuation; partial volume effect, etc.), by the lack of absolute quantitative measurements and by difficulties in the analysis of regional data. Nevertheless, the present report indicates the importance of a non-invasive tomographic monitoring of the cerebral perfusion after EC-IC bypass surgery, especially as changes observed early in the post-operative phase may not be representative of the final perfusional state. Therefore only physiological investigations that are not limited to short term effects will be able to evaluate the real usefulness of this as well as other forms of surgical therapy.

The authors express their thanks to $\mathrm{O}$ Arena, M C Gilardi, G Lucignani, P Pantano, and C Rossetti for helpful advice and support, to $M$ Carenzi and
C Mattei for assistance and to A Losito for secretarial help.

This work was partly supported by C.N.R. Grants Nos 85.00634.56 and 85.00485.04.

\section{References}

1 The EC/IC Bypass Study Group. Failure of extracranialintracranial arterial bypass to reduce the risk of ischaemic stroke. Results of an International Randomized Trial. $N$ Engl J Med 1985;313:1191-200.

2 Editorial. Extracranial to intracranial bypass and the prevention of stroke. Lancet 1985;2:1401-2.

3 Heilbrun MP, Reichman OH, Anderson RE, Roberts TS. Regional cerebral blood flow studies following superficial temporal-middle cerebral artery anastomosis. J Neurosurg 1975;43:706-16.

4 Gratzl O, Schmiedek P, Spetzler R, Steinhoff H, Marguth F. Clinical experience with extra-intracranial arterial anastomosis in 65 cases. $J$ Neurosurg 1976; 44:313-24.

5 Reichman $\mathrm{OH}$. Neurosurgical microsurgical anastomosis for cerebral ischemia: 5 years' experience. In: Scheinberg P, ed. Princeton Conference on Cerebrovascular Disease. New York: Raven Press, 1976: 311-37.

6 Holbach KH, Wassmann H, Hoheluchter KL, Jain KK. Differentiation between reversible and irreversible post-stroke changes in brain tissue: its relevance for cerebrovascular surgery. Surg Neurol 1977;7:325-31.

7 Roski R, Spetzler RF, Owen M, Chandar K, Sholl JG, Nulsen FE. Reversal of seven-year-old visual field defect with extracranial-intracranial arterial anastomosis. Surg Neurol 1978;10:267-75.

8 Binder LM, Tanabe CT, Waller FT, Wooster NE. Behavioral effects of superficial temporal artery to middle cerebral artery bypass surgery: preliminary report. Neurology 1982;32:422-4.

9 Nielsen H, Hojer-Pedersen E, Gulliksen G, Haase J, Enevoldsen E. A neuropsychological study of 12 patients with transient ischemic attacks before and after EC/IC bypass surgery. Acta Neurol Scand 1985;71:317-20.

10 Kung HF, Tramposch KM, Blau M. A new brain perfusion imaging agent: (I-123) HIPDM: N,N,N'trimethyl-N'-(2-hydroxy-3-methyl-5-iodobenzyl)-1,3propanediamine. J Nucl Med 1983;24:66-72.

11 Fazio F, Lenzi GL, Gerundini $P$, et al. Tomographic assessment of regional cerebral perfusion using intravenous I-123-HIPDM and a rotating gamma-camera. J Comput Assist Tomogr 1984;5:911-21.

12 Lucignani G, Nehlig A, Blasberg R, et al. Metabolic and kinetic considerations in the use of (125-I)HIPDM for quantitative measurements of regional cerebral blood flow. J Cereb Blood Flow Metab 1985;5:86-96.

13 Fazio F, Fieschi C, Collice M, et al. Tomographic assessment of cerebral perfusion using a single-photon emitter (Krypton-81 $\mathrm{m}$ ) and a rotating gamma camera. J Nucl Med 1980;21:1139-45.

14 Powers WJ, Grubb RL Jr, Raichle ME. Physiologic responses to focal cerebral ischemia in humans. Ann 
Neurol 1984;16:546-52.

15 Frackowiak RSJ, Lenzi GL, Jones T, Heather JD. Quantitative measurement of cerebral blood flow and oxygen metabolism in man using ${ }^{15} \mathrm{O}_{2}$ and positron emission tomography: theory, procedure and normal values. J Comput Assist Tomogr 1980;4:727-36.

16 Baron JC, Bousser MG, Rey A, Guillard A, Comar D, Castaigne P. Reversal of focal "misery-perfusion syndrome" by extra-intracranial arterial bypass in hemodynamic cerebral ischemia. Stroke 1981;12: 454-59.

17 Grubb RL Jr, Ratcheson RA, Raichle ME, Kliefoth AB, Gado MH. Regional cerebral blood flow and oxygen utilization in superficial temporal-middle cerebral artery anastomosis patients. An exploratory definition of clinical problems. J Neurosurg 1979;50:733-41.

18 Baron JC, Rey A, Guillard A, Bousser MG, Comar D, Castaigne $P$. Non invasive tomographic imaging of cerebral blood flow and oxygen extraction fraction in superficial temporal artery to middle cerebral artery anastomosis. In: Meyer JS, Lechner $\mathrm{H}$, Reivich $\mathbf{M}$, Ott EO, Aranibar A, eds. Cerebrovascular Disease 3. Amsterdam: Excerpta Medica, 1981:58-64.

19 Powers WJ, Martin WRW, Herscovitch P, Raichle ME, Grubb RL. Extracranial-intracranial bypass surgery: hemodynamic and metabolic effects. Neurology 1984; 34:1168-74.

20 Samson Y, Baron JC, Bousser MG, et al. Effects of extra-intracranial arterial bypass on cerebral blood flow and oxygen metabolism in humans. Stroke 1985;16:609-16.

21 Yamamoto YL, Little J, Thompson C, Meyer E, Feindel W. Positron tomography with Krypton-77 for evaluation of topographical rCBF changes following EC-IC bypass surgery. Acta Neurol Scand 1979;60(suppl 72):522-3.

22 Little JR, Yamamoto YL, Feindel W, Meyer E, Hodge CP. Superficial temporal artery to middle cerebral artery anastomosis. Intraoperative evaluation by fluorescein angiography and Xenon-133 clearance. $J$ Neurosurg 1979;50:560-9.

23 Laurent JP, Lawner PM, O'Connor M. Reversal of intracerebral steal by STA-MCA anastomosis. $J$ Neurosurg 1982;57:629-32.

24 Carter LP, Crowell RM, Sonntag VKH, Spetzler RF. Cortical blood flow during extracranial-intracranial bypass surgery. Stroke 1984;15:836-9.

25 Halsey JH Jr, Morawetz RB, Blauenstein UW. The hemodynamic effect of STA-MCA bypass. Stroke 1982;13:163-7.

26 Schmiedek P, Gratzl O, Spetzler R, et al. Selection of patients for extra-intracranial arterial bypass surgery based on rCBF measurements. J Neurosurg 1976; 44:303-12.

27 Awad I, Little JR, Bryerton B, Furlan AJ. Regional cerebral blood flow in extracranial-intracranial bypass surgery. J Cerebr Blood Flow Metab 1983; 3:S596-7.

28 Meyer JS, Nakajima S, Okabe T, et al. Redistribution of cerebral blood flow following STA-MCA bypass in patients with hemispheric ischemia. Stroke 1982;13: 774-84.

29 Yonekura M, Austin G, Hayward W. Long-term evaluation of cerebral blood flow, transient ischemic attacks, and stroke after STA-MCA anastomosis. Surg Neurol 1982;18:123-30.

30 Younkin D, Hungerbuhler JP, O'Connor M, et al. Superficial temporal-middle cerebral artery anastomosis: Effects on vascular, neurologic, and neuropsychological functions. Neurology 1985;35:462-9.

31 Tanahashi N, Stirling Meyer J, Rogers RL, et al. Longterm assessment of cerebral perfusions following STA/MCA by-pass in patients. Stroke 1985;16:85-91.

32 Vorstrup S, Lassen NA, Henriksen L, et al. CBF before and after extracranial-intracranial bypass surgery in patients with ischemic cerebrovascular disease studied with 133Xe-inhalation tomography. Stroke 1985; 16:616-26.

33 Kastrup J, Sjyhoj Olsen T, Christensen J, Sugiyama H, Parving $\mathrm{HH}$, Lassen NA. A comparison between tomographic and non-tomographic cerebral blood flow methods. $r C B F$ Bulletin 1986;9:179-83.

34 Martin WRW, Baker RP, Herscovitch P, Zeiger HE, Grubb RL, Raichle ME. The selection of patients for extracranial-intracranial bypass surgery: hemo- dynamic and metabolic criteria. Neurology 1982;32: A89.

35 Norrving B, Nilsson B, Risberg J. rCBF in patients witho carotid occlusion. Resting and hypercapnic flow related to collateral pattern. Stroke 1982;13:155-62.

36 Gibbs JM, Wise RJS, Leenders K, Jones T. Evaluation of cerebral perfusion reserve in patients with carotidartery occlusion. Lancet 1984;1:310-4.

37 Martin WRW, Baker RP, Grubb RL, Raichle ME. Cerebral blood volume, blood flow, and oxygen metabolism in cerebral ischaemia and subarachnoid haemorrhage: an in-vivo study using positron emission tomography. Acta Neurochirurg 1984;70:3-9.

38 Gibbs JM, Wise RJS, Mansfield AO, Ross Russel R, Thomas DJ, Jones T. Regional cerebral blood flow and blood volume before and after EC-IC bypass surgery and carotid endoarterectomy in patients with occlusive carotid disease. J Cereb Blood Flow Metab 1985;5:S19-S20.

39 Symon L, Crockard HA, Dorsch NWC, Branston NM, Juhasz J. Local cerebral blood flow and vascular reactivity in a chronic stable stroke in baboons. Stroke 1975;6:482-92.

40 Barnett HJM, Peerless SJ, McCormick CW. In answer to the question: "as compared to what?" A progress report on the EC/IC bypass study. Stroke 1980;11: $137-40$. 